This is a postprint version of the following published document:

Ferreira, José Luis; Gilboa, I.; Maschler, M. Credible Equilibria in Games with Utility Changing during the Play. Games and Economic Behavior. Aug. 1995, vol. 10, n. 2, p. 284-317. Available in: http://dx.doi.org/10.1006/game.1995.1033

(c) Elsevier

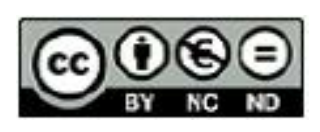

This work is licensed under a Creative Commons Attribution-NonCommercialNoDerivatives 4.0 International License. 


\title{
Credible Equilibria in Games with Utilities Changing during the Play
}

\author{
J.-L. FERREIRA \\ Universidad Carlos III de Madrid, Madrid, Spain \\ I. GilboA \\ Northwestern University, Evanston, Illinois
}

AND

M. MASCHLER*

The Hebrew University, Jerusalem, Israel

\begin{abstract}
Whenever one deals with an interactive decision situation of long duration, one has to take into account that priorities of the participants may change during the conftict. In this paper we propose an extensive-form game model to handle such situations and suggest and study a solution concept, called credible equilibrium, which generalizes the concept of Nash equilibrium. We also discuss possible variants to this concept and applications of the model to other types of games. American Mathematical Society Classification Numbers: 90A06, 90A07, 90A43, 90A56, 90D06, 90D10, 90D35, 90D40, 90D80. Journal of Economic Literature Classification Numbers: C70, C72, D10, D11, D80, D83.
\end{abstract}

\footnotetext{
* We express our thanks and gratitude to Chaim Fershtman and Ehud Kalai for several conversations, from which we benefitted greatly. In particular, Chaim Fershtman pointed out to us that games with changing utilities require further analysis, thus originating this research. Ehud Kalai, among other good suggestions, insisted that we verify Theorem 4.1. A special thanks is due to an anonymous referee, whose remarks enabled us to improve the presentation a great deal. We are grateful to Northwestern University and to the University of Tilburg. The Netherlands for the hospitality extended to some of us, while this research was conducted. The second author gratefully acknowledges NSF Grant SES-9113108.
} 


\section{INTRODUCTION}

As far as we know, a game in which priorities change during the play was first discussed by Homer in the story of Odysseus/Ulysses and the sirens (Odyssey, ca 10th century B.C.). According to the story, the singing of the sirens was renowned for its beauty and so seductive that whoever heard it was lured to his death.

Odysseus achieved his desire to hear the singing of the sirens in a way that game theorists, often unjustifiably, ignore. He followed the principle' that when people do not like the rules of the game, they change the rules. Thus Odysseus invented a new, pure strategy; namely, he put wax in the ears of each of his sailors, commanding them to tie him to the mast and not to release him until they were safely bound for home.

Lacking the creativity and imagination of Homer, we shall not follow this avenue and regard our games as given and fixed.

Classical economics and game theory assume that an individual's preferences are constant throughout the decision-making process, even if the latter has several stages. This seemingly implausible assumption is of great theoretical value; in particular, it allows a multi-stage decision problem to be "collapsed" to a single-stage one (see, e.g., Savage, 1954) and enables an extensive game to be represented in a "normal" form, etc.

Yet, the fact that preferences may well change over time has been bothering economic theorists for over four decades. Allais (1947) was probably the first (in modern times) to deal with "exogenously" changing preferences, i.e., preferences which depend on time alone. "Endogenous" changes in preferences, namely those resulting from the actions of the decision-maker or other players, were studied in the early 1950's (see Schoeffler, 1952, and Harsanyi, 1953).

Situations in which priorities change are plentiful; people change and events influence our perception of the world. When one is young one loves junk food, both for its taste and for the opportunity its consumption gives to meet young friends, old and new, and to have a great time with them. As one gets older, one's stomach becomes more sensitive, one also associates with different people, so junk food is no longer attractive. When one is young, one wants to spend a lot of time on leisure; when one gets older, providing for one's family takes priority. One might enjoy watching ceremonies of queer cults, but there is a positive probability that one may become brainwashed, desert one's family, and follow the cult-a prospect that is not attractive before going to the ceremony. The reader can certainly provide many more examples of changing priorities.

It is wise to take into account the possibility of changing priorities in

\footnotetext{
' Expressed by Martin Shubik (oral comunication).
} 
any long-range plan. The question then becomes how to model these situations and what strategies to recommend, as well as what strategies are likely to be played. That is the subject of this paper.

We wish to emphasize ${ }^{2}$ that we wish to analyze these situations in terms of classical utility theory and classical game theory; namely, we want to show that classical views can be applied just as well when preferences change, provided that one is very careful about the interpretation of the various concepts. We take great care to give at least one precise interpretation, realizing, of course, that other interpretations may be appropriate just as well, but they have to be stated precisely, if one wants to apply our model correctly.

Even a brief survey of the literature is beyond the scope of this paper. A very partial list of relevant works includes Strotz (1956), Pollak (1968), Phelps and Pollak (1968), Pollak (1970), Von Weissaecker (1971), Blackorby, Nissen, Primont, and Russell (1973), Peleg and Yaari (1973), Hammond (1976), and Pollak (1976). We will briefly discuss some of these in Section 3, as a background to the presentation of our solution concept.

In Section 2 we present an extensive form model and discuss its relevance to our topic. In Section 3 we propose strategy combinations, which we call credible equilibria, to handle the above situations. In Section 4 we show that the set of credible equilibria is identical to the set of Nash equilibria if priorities do not change during the play. Thus, our solution is an extension of the Nash non-cooperative solution to situations in which priorities change during the play. We then prove, among several other results, that the set of credible equilibria contains the set of perfect equilibria of the agent-form game; hence it is never empty. Section 5 studies the set of credible equilibria. It shows, among other things, that a credible equilibrium path is also a path of a Nash equilibrium for the agent-form game. Section 6 provides some examples designed to illustrate characteristics of credible equilibria. Section 7 shows that an extension of the concept to a model in which time is a part of the data does not yield new equilibrium points. Section 8 discusses some possible variants of the concept.

Basically, we are dealing in this paper with individuals having various utilities during the play of a game. This suggests that our model could be applied to another, very important class of situations, where a player is a group of individuals, a state, a party, etc. Such a player is to some extent a decision-making unit, but it does not have a utility of its own. Rather, it represents various groups, each endowed with its own utility function. For example, a state may represent farmers, manufacturers, ordinary citizens, etc., but there is no such thing as "a utility of the state." In Section 9 we discuss the applicability of our model to such situations

${ }^{2}$ We are grateful to an anonymous referee for this remark. 
and show that the scope of such application is limited. Thus, an extension of our model is highly desirable.

\section{THE MOdEL}

We start with a game form ${ }^{3}(T, P, U, C, p)$. Here, $T$ is a tree, $P=\left\{P_{0}\right.$, $\left.P_{1}, \ldots, P_{n}\right\}$ is the players' partition ${ }^{4}$ of the nodes of $T\left(P_{0}\right.$ is the set of Chance's nodes); $U=\left(U_{0}, U_{1}, \ldots, U_{n}\right)$, where $U_{i}=\left\{u_{i j}\right\}_{j=1}^{k_{i}}$ is the partition of $P_{i}$ into information sets ${ }^{5}$ (elements of $U_{0}$ are singletons); $C=$ $\left\{C\left(u_{i j}\right)\right\}_{i=1,2 \ldots, n j=1,2, \ldots, k_{i}}$ is a correspondence, where $C\left(u_{i j}\right)$ is the set of choices which are available to player $i$ at information set $u_{i j} ; p=$ $\left\{p\left(u_{0 j}\right)\right\}_{j=1,2, \ldots, k_{0}}$ is a vector-valued function, where $p\left(u_{0 j}\right)$ is a probability distribution on Chance's choices at $u_{0 j}$. For further information concerning this notation see, e.g., Selten (1975).

We assume that the game form is a game of perfect recall in the sense of the following definition (taken from Selten, 1975).

Definition 2.1. A game form $(T, P, U, C, p)$ is said to be of perfect recall if, for every $i, i=1,2, \ldots, n$, and every two information sets $u_{i j}$ and $u_{i k}$ of the same player $i$, if one node $y, y \in u_{i k}$, comes after ${ }^{b}$ a choice $c$ at $u_{i j}$, then every node $x$ in $u_{i k}$ comes after the same choice $c$.

By Kuhn's theorem (Kuhn, 1953; Selten, 1975), we can and will restrict ourselves to behavioral strategies.

We shall also talk about the derived agent-form game, obtained by placing, for each $i$, different agents $i, j$ at the different information sets $u_{i j}$ of player $i$. Each agent $i . j$ will play dual roles: on the one hand, we shall regard him as a decision-making unit that acts in accordance with his own utility function; on the other hand, in reality he is the same player $i$ located at a certain stage of the play. To complete the description of our model, we endow each agent $i, j$ with a von Neumann-Morgenstern utility function $h_{i, j}$, defined on lotteries over endpoints of $T$ (which represent pure outcomes). Formally, therefore, our game with utilities ${ }^{7}$ changing during the play is a six-tuple

\footnotetext{
${ }^{3}$ I.e., a game in extensive form without payments at the endpoints.

${ }^{4}$ The players are $1,2, \ldots, n$. "Chance" is denoted by 0 .

${ }^{5}$ To complete the description, we add that for each information set $u_{i j}$ there are $m\left(u_{i j}\right)$ edges going out from each node of $u_{i j}$. They are grouped into $m\left(u_{i j}\right)$ disjoint equivalence classes, where each equivalence class consists of one edge from each node of $u_{i j}$. The equivalence classes are called the choices. We allow information sets with a single choice.

${ }^{6}$ I.e., the path from the root to $y$ contains an arc of choice $c$.

"We use the word "preferences" when we discuss the "real" situation. Their representations in the mathematical model will usually be called "utilities."
} 


$$
\Gamma=(T, P, U, C, p, h)
$$

where $T, P, U, C, p$ are as above, and $h=\left(h_{1}, h_{2}, \ldots, h_{n}\right)$, where, for an endpoint $z$,

$$
h_{i}(z)=\left(h_{i .1}(z), h_{i .2}(z), \ldots, h_{i, k_{i}}(z)\right)
$$

For some $j$ 's, and in particular for all $j$ 's such that $i, j$ lies on the path from the root to endpoint $z, h_{i, j}(z)$ is the utility payment of agent $i, j$ for the endpoint $z$ of $T$. For other $j$ 's $h_{i, j}(z)$ is allowed to be undefined.

Discussion. The above construction comes to model a non-cooperative game in extensive form, in which the players' priorities may change during the play. To understand the relation between "reality" and our model, we provide some explanation and also discuss a possible objection to the model.

(1) As in classical game theory, an "outcome," represented by an endpoint $z$ of $T$, is the aggregate of everything that happens along the path from the root to the endpoint.

(2) We shall be interested in this paper in certain equilibrium points which, in one application, can be viewed as possible agreements that can be reached by the players at the start of the game. For this application, every decision must be based on what the players think at the start of the game. Accordingly, the function $h_{i, j}$ should be interpreted as that utility function player $i$ believes at the start of the play he will have when he reaches information set $u_{i j}$. We use here the words "believe" or "knows" in the sense of "ascribing probability one." (See the discussion in Aumann and Brandenburger, 1995, concerning the relevance of this meaning.) Thus, we allow for the possibility that later on a player will find out that what he knew was wrong, in ways that he did not expect at all. When a person takes a decision, the only thing that matters is what he knows, or believes, at the moment that the decision takes place.

(3) We assume that player $i$ knows his utility function $h_{i, j}$. There is no loss of generality in this assumption. If he is not sure, being a Bayesian, he has some probability distribution over various possible utility functions. This he can represent by introducing chance moves as done in Harsanyi's theory of games with incomplete information (Harsanyi, 1967-1968). Similarly, there is no loss of generality in assuming that all components of $\Gamma$ (in (2.1)) are common knowledge.

(4) The utility functions are merely numerical expressions for the agents' preferences. Thus, tautologically one expects each agent to act in accordance with maximization of his own utility function. This trivial 


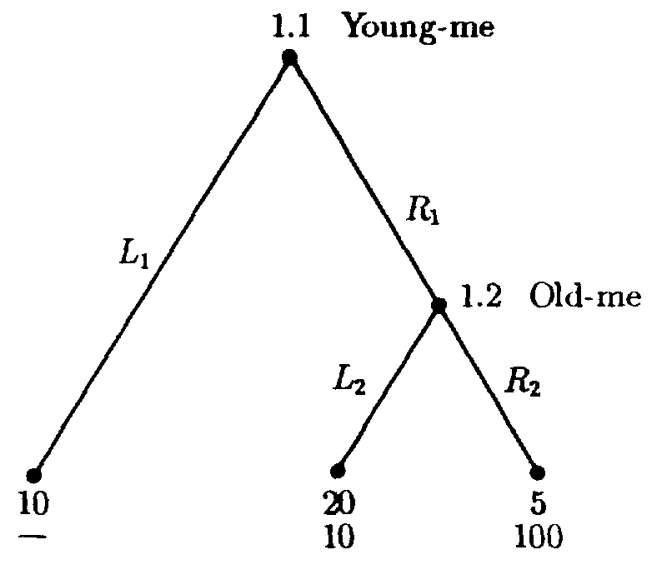

FIG. 1. The young/old me game.

remark is not always understood, and the misunderstanding leads to a lot of confusion. Consider the 1-person game of Fig. 1.

In this game $L_{1}$ and $L_{2}$ mean "spend on holiday vacations" and $R_{1}$ and $R_{2}$ mean "save for home for the aged." We heard again and again that the right thing for agent 1.1 to do is to take $R_{1}$. Indeed, agent 1.2 will certainly choose $R_{2}$, so agent 1.1 should cooperate in order to eventually enjoy a good home for the aged (100 is a pretty large number!). This reasoning is totally wrong: Had young-me cared for old-me, this should have been reflected in 1.1's utility function. But the data shows clearly that young-me prefers to spend money on vacations rather than worry about old age. In fact, his preference is for travel when he becomes old (see the 20), but he believes that, as an old person, his priorities will be different; therefore, he has no chance of getting the 20. Even without a theory, it should be clear that the "right" solution for this game ${ }^{8}$ should be $L_{1} R_{2}$.

(5) Another question that is frequently asked is this: Why do we need a new model? Is not the change of utilities simply a matter of gaining experience, or learning? To explain this, let us compare the game in Fig. 1 with the one in Fig. 2.

In this game, player 1 is a person who cannot stand modern music. $\mathrm{He}$ believes, however, that if he takes a course in modern music, he will get

\footnotetext{
${ }^{8}$ For those who are not convinced, let us replace the meaning of $L_{1}, L_{2}$ to be "stay home," and $R_{1}, R_{2}$ to be "consume heroin," Agent 1.2 is already addicted to heroin. Would one still claim that a rational agent 1.1 should choose $R_{1}$ ?
} 


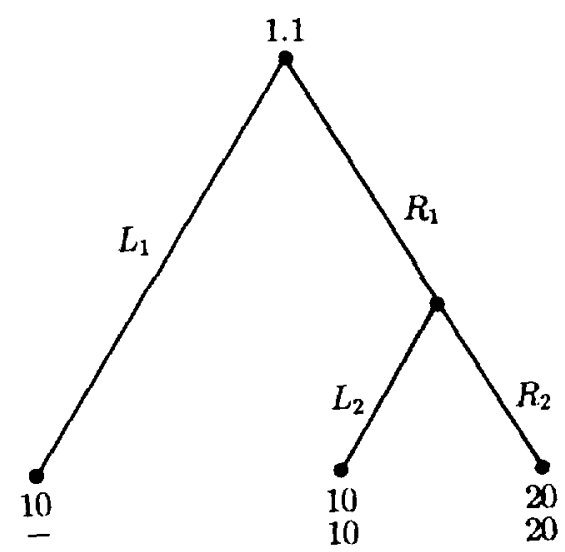

FIG. 2. Taking a course in modern music.

accustomed to this kind of music and learn to love it. $L_{1}, L_{2}$ mean "stay home". $R_{1}$ means "take the course". $R_{2}$ means "listen to modern music". 9

In this case, contrary to the previous example, there is no change in the priorities of the agents. The utilities of the agents remain the same, in as much as they are defined. Player 1 expects to learn how to enjoy modern music and his expectation from the course matches what he believes will be after he takes the course. This example is equivalent to the ordinary 1-person game of Fig. 3.

(6) A possible objection to our model is this: Following logical positivism, some people feel that to talk about priorities is sheer "metaphysical nonsense" if they are not derived by observing actual decisions. According to this view, utilities must be derived form actual revealed preferences. If only revealed preferences count, it makes no sense to talk about revealed preferences of a future agent. How can one observe at the present time commitments to be taken 20 years from now? This is a serious criticism and it requires an honest answer ${ }^{10}$ :

(i) This is a criticism of the whole field of game theory, not only of our model. In fact, there is hardly any application of game theory that is based on actual measurements of utilities. Game

\footnotetext{
${ }^{9}$ We put a blank as a utility for agent 1.2 after $L_{1}$, because it makes no sense to talk about the utility of an "educated" person (agent 1.2) for the prospect of not being educated. However, we could define agent 1.2 as an agent of player I at a date when the course is over. With this interpretation, the blank could have been replaced by 10 .

${ }^{10}$ This objection was raised also in Peleg and Yaari (1973).
} 


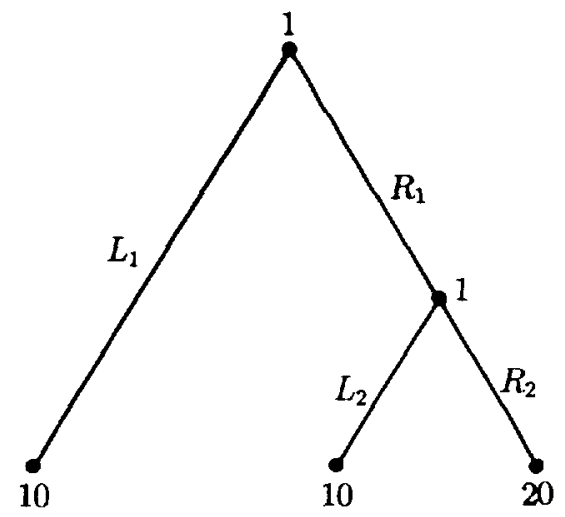

FIG. 3. A classical representation of the previous game.

theory (including our model, we hope) is useful for the insight it sheds on real situations, for recommendations based on rough evaluation of priorities, for theoretical analysis, and for clarification of issues. But we have to admit that actual measurements of utilities are usually impossible and, in those cases where they are possible, they are unreliable. In this connection see Aumann (1985).

(ii) The belief that only revealed preferences count does not make much sense. ${ }^{11}$ It can be criticized both on practical and theoretical grounds; with this belief one cannot measure, with any reasonable degree of precision, a cardinal utility such as the utility of von Neumann and Morgenstern. This is because one cannot present the players with simultaneous revealed-preference situations. What is done cannot be undone, and once a commitment is taken (if taken seriously), it cannot be cancelled.

The conceptual difficulty that we have with the revealedpreference view is this: Suppose you decide, by observing some of this actions, that a player prefers $A$ to $B$ and $B$ to $C$. What reason do you have to believe that he would have manifested the same priorities had the choices been presented to him in a different order? Experiments that cannot be repeated are of little value! Thus, restriction to revealed preferences is not only useless, it is also questionable.

(iii) Whether we like it or not, people seldom measure utilities.

"We employ here the tactic that an attack is the best defense. 
They deduce their priorities (and the priorities of others) by introspection. To be sure, past experience takes part in this act of introspection and this includes observations of revealed preferences in similar situations in the past, but the botom line is that important decisions are derived from priorities that result from introspection. It is these priorities that count, even if they cannot be measured by an outside observer. ${ }^{12}$ Now, if we are talking about introspection, it does not matter much if we discuss a present situation or a future one. If I want to estimate my priorities, say 20 years from now, I shall observe conditions and behavior of old people, perhaps look at rudimentary available statistics about their illnesses and sufferings, and also look for things that make them happy. I shall combine these facts (consciously or subconsciously) with what I think I know about myself and-rightly or wrongly-deduce my future priorities by introspection. It is the outcome of my introspection that will dictate my decisions.

To sum up: Attempts to determine von Neumann-Morgenstern utilities by observing people's behavior did not prove successful. In fact, experts on experimental economics ${ }^{13}$ claim that real people do not seem to behave as utility maximizers. One can take a view, as expressed by John Harsanyi ${ }^{14}$ that game theory is a theory about ideal people-people who do not exist in the real world, and enjoy the subject for its aesthetic value. In this sense our model is certainly as useful as the classical one. And we can be more flexible, recognize that decisions are made by the process of introspection, the results of which govern the players' actions. Utility theory and game theory can help the decision-maker by leading his thoughts to the required priority determinations, thereby "educating" him to be more systematic and logical, hoping that with this help his decisions will be reached faster and with fewer "oversights." At any rate, both conceptually and practically, introspections about future prospects are not more complicated than introspections about the present.

All the above has very little to do with another main application of game theory; namely, to shed more light on conflict situations and to deepen our understanding of the conflict per se, even though in reality most conflicts cannot be quantified. In this respect, our model is certainly an interesting and useful extension of the classical one.

\footnotetext{
${ }^{12}$ Savage already recognized their importance when he discussed "conceivable acts" (Savage, 1972).

${ }^{13}$ Oral communication with Reinhard Selten and Martin Shubik.

${ }^{14}$ Oral communication.
} 
The purpose of this paper is to generalize the concept of Nash equilibrum to games with utilities changing during the play.

One idea that comes to mind is to recommend an agent-form Nash equilibrium. It seems that such an equilibrium is satisfactory; no agent will deviate because, by deviation alone, he has nothing to gain. Indeed, this recommendation was studied in the important paper of Peleg and Yaari (1973). Nevertheless we now feel that this recommendation is not good enough. The reason is that Nash equilibrium is robust with respect to a deviation of a single agent-not against deviation of several agents. But several agents of the same player can cooperate quite easily, to the benefit of all of them, because they are all the same individual. Thus, an agent-form Nash equilibrium is not necessarily stable. It seems that what we need is some kind of coalition-proof equilibrium, ${ }^{15}$ where coalitions are restricted to agents of the same player. Unfortunately, if we extend that definition directly, we may easily reach situations in which no such equilibrium exists. Moreover, we may injustifiably reject "good" points: Suppose a strategy combination is rejected because a certain coalition of agents of a player can deviate and do better-it may well be that this deviation will not be obeyed, because some agents of the same player (not necessarily a subset of the deviating players) can do better after the deviation is "adopted" and cause loss to some members of the deviating coalition. If this is the case, the original strategy combination seems to us quite reasonable.

To overcome the above difficulties, we introduce here the concept "credible deviation," defined recursively, and define "credible equilibrium" as one at which no credible deviations exist.

To make things precise, we need to establish some notation. Let $\Gamma=$ $(T, P, U, C, p, h)$ be a game of perfect recall with utilities changing during the play. A behavioral strategy $s_{i, j}$ of agent $i . j$ is a probability distribution over the choices $c_{i j}$ at $u_{i j}$. We note by $S_{i, j}$ the set of these strategies. A behavioral strategy for player $i$ is the $k_{i}$-tuple $s_{i}:=\left(s_{i .1}, s_{i .2}, \ldots, s_{i . k_{i}}\right)$, where $s_{i, j}$ belongs to $S_{i, j}$. Thus, the set of behavioral strategies for player $i$ is $\times_{j=1}^{k_{i}} S_{i, j}=: S_{i}$. An $n$-tuple of behavioral strategies is $s=\left(s_{1}, \ldots, s_{n}\right)$ and the set of these $n$-tuples, called also "points" is $S=\times_{i=1}^{n} S_{i}$.

Let $Q$ be a set of agents (to be thought of as belonging to the same player). We denote by $-Q$ the set $M \backslash Q$, whee $M$ is the set of all agents (not only of the same player). For a point $s$, we denote by $s_{Q}$ the vector of strategies ${ }^{16}\left(s_{i, j}\right)_{i, j \in Q}$. Similarly, $S_{Q}:=\times_{i, j \in Q} S_{i, j}$. For simplicity we also

${ }^{15}$ A concept that was introduced in Bernheim, Peleg, and Whinston (1987) and in Peleg (1992).

${ }^{16}$ Strictly speaking, we should fix an order on the agents to make it a vector. 
write $\left(s_{-i, j}, s_{i, j}^{\prime}\right)$ which expresses a deviation of agent $i . j$ to $s_{i, j}^{\prime}$, instead of the more precise notation $\left(s_{-\{i . j\}}, s_{i, j}^{\prime}\right)$.

Given an $n$-tuple of behavioral strategies $s$, it induces a probability distribution on the endpoints. Thus, we can denote by $j_{i j}(s)$ the utility of agent $i . j$ for this lottery. For $s$ and $s^{\prime}$ in $S$, we write $s^{\prime}>_{i, j} s$ iff $h_{i, j}\left(s^{\prime}\right)>$ $h_{i, j}(s)$.

Finally, for a given $s$ and a given agent $i . j$, we denote by $\Gamma_{i, j}^{s}$ the game obtained from $\Gamma$ by converting the strategy of every agent, other than the strategies of $i, j$ and the agents of player $i$ that play after him, ${ }^{17}$ to chance mechanisms playing as in $s$ (and converting the information sets of the chance mechanisms to singletons). $\Gamma_{i, j}^{s}$ is the game that the players think at the start of the game that agent $i . j$ is facing, given that every agent other than he and his followers follow $s$. Note that $\Gamma_{i, j}^{s}$ is a 1-person game-possibly with several agents.

We can now introduce our solution concept. Note that, because the game is of perfect recall, the probability distributions on the nodes of the information sets of agents of player $i$, given that they are reached, depend only on the strategy $(n-1)$-tuple ${ }^{18} s_{-i}$ and not on $s_{i}$. Indeed, if a nonsingleton information set of an agent $i . j_{0}$ is reached, all previous choices taken by player $i$ are known, the information set results from not knowing choices taken by chance and by other players. The probabilities on its nodes can be calculated from $p$ and $s_{-i}$.

Definition 3.1. Let $\Gamma=(T, P, U, C, p, h)$ be a game of perfect recall with utilities changing during the play. Let $s$ be an $n$-tuple of behavoral strategies. Let $Q$ be a set of agents of player $i, i \neq 0$, containing an agent $i . j_{0}$ and possibly some of $i$ 's agents that play after $i . j_{0}$. A strategy $|Q|$-tuple $s_{Q}^{\prime}$ is said to be a credible deviation from $s$, struck by agent $i . j_{0}$ using $Q$. if:

(i) $s^{\prime}>_{i, j_{0}} s$, where $s^{\prime}:=\left(s_{Q}^{\prime}, s_{-Q}\right)$; i.e., agent $i, j_{0}$ strictly prefers that everyone play according to $s^{\prime}$ rather than everyone play according to $s$.

(ii) $s^{\prime}>_{i, j}\left(s_{-i, j}^{\prime}, s_{i, j}\right)$ for all $i, j \in Q, i, j \neq i, j_{0}$. Thus, agent $i, j$ strictly prefers to play $s_{i, j}^{\prime}$ rather than $s_{i, j}$, given that the other agents play as dictated by $s^{\prime}$. We shall refer to this condition by saying that $i, j$ prefers to comply with $s^{\prime}$.

(iii) No agent of $i$, whether in $Q$ or not, that plays after $i . j_{0}$, can strike a credible deviation from $s^{\prime}$.

Note that the definition is not circular, because the relation "plays after" is acyclic.

${ }_{18}^{17}$ We say that $i . j$ plays after $i . j_{0}$ if every path from $u_{i j}$ to the root passes through $u_{i j_{0}}$.

${ }^{18} s_{-i}$ is a short notation for $\left(s_{1}, \ldots, s_{i-1}, s_{i+1}, \ldots, s_{n}\right)$. 
Discussion. We view the deviation from $s$ as a set of instructions $s_{Q}^{\prime}$ given by $i . j_{0}$ to the members of $Q$. We wish to emphasize that $Q$ may consist of $i . j_{0}$ alone. Moreover, each member of $Q$ is an agent of player $i$ and not of any other player. Following the spirit of the concept of Nash equilibrium, agents of player $i$ strike the deviation and agents of other players are supposed to play as agreed in $s$.

Condition (i) states that $i, j_{0}$ prefers that these instructions are obeyed, given that agents of $-Q$ continue $^{19}$ to follow $s$. Indeed, otherwise, why did he give such instructions? Note that this implies that $i . j_{0}$ is reached with positive probability under $s$, because prior to $i . j_{0}$ there is no distinction between elements of $s$ and $s^{\prime}$.

Condition (ii) implies that each member $i . j$ of $Q$ is reached with positive probability under $s^{\prime}$. When $i, j$ comes to play he has two suggested strategies: The original suggestion $s_{i, j}$ dictated by $s$ and the deviation suggestion $s_{i, j}^{\prime}$. Which one will he obey? The condition states that each member of $Q$, except ${ }^{20}$ perhaps $i . j_{0}$, actually prefers to comply with $s^{\prime}$. In other words, when $i, j$ of $Q$ comes to play (equivalently, when $i . j$ considers playing in $\left.\Gamma_{i, j}^{s^{\prime}}\right)$, he prefers $s_{i, j}^{\prime}$ to $s_{i, j}$, given that other agents follow $s^{\prime}$. Thus, such an agent has an incentive to follow the instructions. Following the spirit of Nash equilibrium, we took the position that even if $i . j$ is indifferent between $s_{i, j}^{\prime}$ and $s_{i, j}$, he will not switch ${ }^{21}$ to $s_{i, j}^{\prime}$.

But there remains some doubt: What guarantees to the agents that every agent of $i$ will indeed follow $s^{\prime}$ ? Could not it happen that they "agree" on $s_{Q}^{\prime}$ and one of them, whether in $Q$ or not, strikes later a credible deviation from $s^{\prime}$ ? Condition (iii) is introduced to prohibit this possibility. The players that come to play after $i . j_{0}$ can rest assured that none of them can deviate from $s^{\prime}$ and do better in a credible way. This is true not only for members of $Q$, but also for agents of $i$ not in $Q$. Condition (iii) gives our definition a recursive flavor, and it works because, for every agent $i . j$ after $i . j_{0}$, the " $i$-length" 22 of $\Gamma_{i, j}^{s^{\prime}}$ is smaller than the $i$-length of $\Gamma_{i, j_{0}}^{s^{\prime}}$.

Remark. Although it is reasonable to assume that an agent of $i$ not only remembers what choices other agents of $i$ took in the past, but also knows by what probability distribution they were obtained, we do not make this assumption. So, if, say, an agent $i . j_{1}$, decides to "cheat" and move from a completely mixed strategy $s_{i, j_{1}}$ to another one, any agent $i . j_{2}$ after him will not recognize that cheating took place. As has been said above, knowing $s_{-i}$ and knowing that he was reached, is sufficient, in a

\footnotetext{
${ }^{19}$ Subsequently we shall see that he can count on this.

${ }^{20}$ This exception was put in order to allow for $i, j_{0}$ to continue using $s_{i, j_{0}}$. If other agents are asked to continue using $s_{i, j}$, we simply do not include them in $Q$.

${ }^{21}$ One could think of a different position (see Section 8).

${ }^{22} \mathrm{By}$ " $i$-length" we mean the longest path from an agent $i . j, i \neq 0$, to an endpoint.
} 


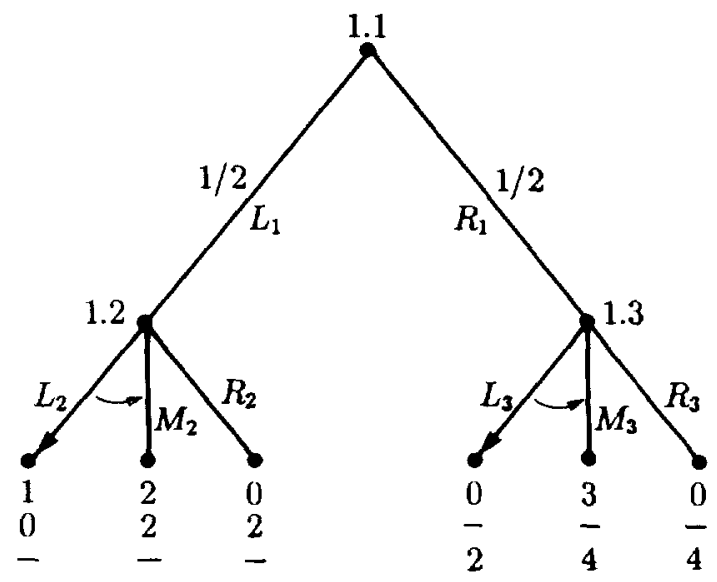

FIg. 4. A credible deviation that will be violated.

game of perfect recall, for agent $i . j_{2}$ to compute all the probabilities at his information set. In fact, sometimes an agent $i . j$ can predict that $i . j_{0}$ was cheating and this will not change his evaluation and behavior, as the next example shows.

Example 3.2. Consider the 1-player 3-agent game of Fig. 4. Let $s_{1.1}=\left(\frac{1}{2}, \frac{1}{2}\right), s_{1.2}=(1,0,0), s_{1.3}=(1,0,0)$. A credible deviation by 1.1 , using all the agents, may be: $s_{1.1}^{\prime}=\left(\frac{1}{2}, \frac{1}{2}\right), s_{1.2}^{\prime}=(0,1,0), s_{1.3}^{\prime}=(0,1,0)$. It is credible, because after 1.1 plays, every agent is gaining and maximizing under $s^{\prime}$. Nevertheless, 1.1 is actually likely to deviate and play $(0$, 1 ), to get 3 instead of 2.5 . Now, if 1.3 knew that he was cheating he could punish him for his "betrayal," say, by playing $(0,0,1)$, but we do not need to go into such considerations. In fact, we shall later prove (Theorem $5.1)$ that if $i j_{0}$ has a credible deviation from $s$, then he has another credible deviation from $s$ in which it does not pay him to move away.

With the above discussion and remark we can now state our main definition.

Definition 3.3. Let $\Gamma$ be a game with perfect recall and utilities changing during the play. An $n$-tuple $s$ of behavioral strategies is called a credible equilibrium if there are no credible deviations from it; i.e., if there does not exist an agent $i . j_{0}$ and a coalition $Q$ and a vector of behavioral strategies $s_{Q}^{\prime}$ which constitute a credible deviation from $s$.

Remark 3.4. Note that conditions (i)-(iii) of Definition 3.1 impose requirements only on players who play after $i . j_{0}$. Thus, the existence of 
a credible deviation struck by $i . j_{0}$ and the nature of such a deviation do not depend on the utility payments to $i, j_{0}$ and to other agents of $i$, at endpoints that do not follow $u_{i, j_{0}}$. This is important, because, as we already saw, a payment of $i . j_{0}$ need not even be defined at such endpoints, because it may well be that he was not even "created" there.

\section{EXISTENCE THEOREMS}

We start by showing that in ordinary games, the set of Nash equilibria (Nash, 1951) and the set of credible equilibria coincide. This substantiates the claim that we are extending Nash's solution to games with utilities changing during the play.

THEOREM 4.1. Let $\Gamma=(T, P, U, C, p, h)$ be a game of perfect recall in which, for each player, the utility functions of his agents coincide. ${ }^{23}$ Let $\Gamma^{*}$ be the ordinary representation of this game. ${ }^{24}$ The set of credible equilibria ( $\mathrm{CrE}$ ) of $\Gamma$ is equal to the set of Nash equilibria (NE) of $\Gamma^{*}$.

Proof. If $s \in \mathrm{NE}$ in $\Gamma^{*}$ then $s \in \mathrm{CrE}$ in $\Gamma$, because no deviation by an agent of a player, using a set of agents of that player, can satisfy condition (i) of Definition 3.1.

Conversely, if $s \notin \mathrm{NE}$ in $\Gamma^{*}$, then there exists a deviation $s_{Q}^{\prime}$ by player $i$, which is a best reply to $s_{-i}$ and player $i$, and therefore each of his agents, prefers $s^{\prime}:=\left(s_{Q}^{\prime}, s_{-Q}\right)$ to $s$. Let $i, j_{1}, i, j_{2}, \ldots, i, j_{k}$ be the "first members" of $Q$, namely, the members of $Q$ whose paths to the root do not contain other members of $Q$. Because the game is of perfect recall, each agent $i . j_{\nu}, \nu=1,2, \ldots, k$, can compute his expected payoff in $\Gamma_{i, j_{\nu}}^{s}$, both under $s$ and under $s^{\prime}{ }^{25}$ The difference between these expected payoffs depends only on actions taken by the members of $Q_{\nu}:=$ members of $Q$ who are agents in $\Gamma_{i, j_{\nu}}^{s}$. The strategy combination $s_{Q_{v}}^{\prime}$, which is $s^{\prime}$ restricted to $Q_{\nu}$, is a maximizing strategy of player $i$ in $\Gamma_{i, j_{\nu}}^{s}$. Moreover, since $s \notin \mathrm{NE}$, at least one agent, say $i . j_{1}$, is reached with positive probability under $s$ and strictly prefers $s^{\prime}:=\left(s_{Q_{1}}^{\prime}, s_{-Q_{1}}\right)$ to $s$ in $\Gamma_{i, j_{1}}^{s}$. We now modify $s_{Q_{1}}^{\prime}$ by working backwards from the endpoints on members of $Q_{1}$. If an agent $i . j$ in $Q_{1}$, in his turn, is indifferent between $s_{i, j}^{\prime}$ and $s_{i, j}$, given that his information

\footnotetext{
${ }^{23}$ Strictly speaking, we should have added "whenever defined" (see Fig. 2). However, credible equilibria do not depend on utilities of an agent off paths in which he plays, so we might as well assume that the utility functions are defined at all endpoints.

${ }^{24}$ Compare Figs. 2 and 3.

${ }^{25}$ I.e., when his followers in $\Gamma_{i, j}^{s}$, play as dictated either by $s$, or by $s^{\prime}$, respectively.
} 
set is reached ${ }^{26}$ and the strategies of players after him have been already determined, let him switch to $s_{i, j}$. After each switch, player $i$ will still be playing a best reply in $\Gamma^{*}$. After all these switches there will be agents of $Q_{1}$ that are reached with zero-probability under the new strategies. Let them too switch to play as in $s$ (if they have not already switched). Denote by $Q_{2}$ the members of $Q_{1}$ who still play as in $s^{\prime}, Q_{2} \neq \varnothing ; s_{Q_{2}}^{\prime}$ is still a maximizing strategy in $\Gamma_{i, j_{1}}^{s}$. We claim that $s_{Q_{2}}^{\prime}$ is a credible deviation from $s$, struck by $i . j_{1}$. Indeed, we already know that $i, j_{1}$ prefers $s^{\prime}:=\left(s_{Q_{2}}^{\prime}, s_{-Q_{2}}\right) ; Q_{2}$ consists of exactly those agents who prefer to follow $s^{\prime}$ when they come to play. Finally, all agents of $i$ have the same utility function and, after $i . j_{1}$, no agent can do better than the above maximizing strategy; so, no agent after $i . j_{1}$ can strike a credible deviation from $s^{\prime}$.

It follows from Theorem 4.1 that $\mathrm{CrE}$ is not empty for ordinary games of perfect recall. However, we need to establish existence in general as well. This will be done as a corollary to the following theorem which shows that CrE contains the set of agent form perfect equilibria (APE) (see Selten, 1975).

Theorem 4.2. Let $\Gamma=(T, P, U, C, p, h)$ be a game of perfect recall with utilities changing during the play. Let $\Gamma^{*}$ be the agent form game obtained from $\Gamma$ by considering different agents as different players. If $s$ is a perfect equilibrium in $\Gamma^{*}$ then $s$ is credible in $\Gamma$.

Proof, $s$ is a limit of a "test sequence" $\left(s^{k}\right), k=1,2, \ldots$, where $s^{k} \in \mathrm{NE}$ in a "perturbed agent form game" $\Gamma^{k} . \Gamma^{k}$ is a game having the same $T, P, U, C, p, h$ as $\Gamma$, but the behavioral strategies at each choice $c$ are restricted so that the probability to choose $c$ is not smaller than some positive number $\delta_{c}^{k}$, with $\Sigma_{c \in C\left(u_{i j}\right)} \delta_{c}^{k}<1$ for every information set $u_{i j}$, and $\lim _{k \rightarrow x} \delta_{c}^{k}=0$, all $c$.

Suppose that $s$ is not credible in $\Gamma$, then there exists an agent $i . j_{0}$ who can strike a credible deviation $s_{Q}^{\prime}$. Let $i . \ell$ be a last agent ${ }^{27}$ in $Q$. Agent i. $\ell$ prefers to play $s_{i, \ell}^{\prime}$ rather than $s_{i, \ell}$ in $\Gamma_{i, \ell}^{s^{\prime}}$, given that the agents that follow him play as in $s$, because for these agents there is no distinction between $s^{\prime}$ and $s$ and because the deviation was credible. This preference will not change if we modify $s_{i, \ell}^{\prime}$ and $s$ slightly. Modify $s_{i, \ell}^{\prime}$ to $s_{i, \ell}^{\prime \prime}$ which is positive in all components, so that it is a legitimate strategy in $\Gamma^{k}$ for sufficiently large $k$. Modify $s$ to $s^{k}$ and one obtains $s_{i . \ell}^{\prime \prime}>_{i . \ell} s_{i . \ell}^{k}$ in $\left(\Gamma^{k}\right)_{i, \ell}^{s^{\prime \prime}}$ for

\footnotetext{
${ }^{26}$ We also assume that he can be reached with positive probability if player $i$ plays appropriately. Remember that in this case the probability distribution on the nodes of his information set is determined by the strategy combination $s_{-i}$. If he cannot be reached, no matter what $i$ does, he cannot compute the probabilities, but we can safely require that he plays $s_{i, j}$.

${ }^{27}$ Namely, an agent that after him all agents, if exist, play in $s^{\prime}$ as in $s$.
} 


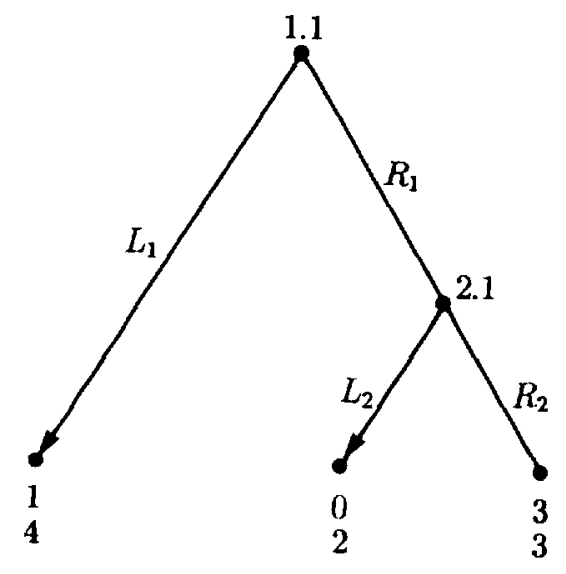

FIG. 5. A credible equilibrium not in APE.

sufficiently large $k$. This means that $s^{k}$ is not in NE in $\Gamma^{k}$, because in $\Gamma^{k}$ $u_{i \ell}$ is reached with positive probability under $s^{k}$, a contradiction.

Corollaray 4.3. The set of credible equilibria is never empty.

Proof. Theorem 4.2 and the fact APE is not empty ${ }^{28}$ (Selten, 1975).

One may wonder if all credible equilibrium points are in APE. That this is not the case even in ordinary games follows from Theorem 4.1 , because there are ordinary games with NE $\neq$ APE. For a simple example which is an ordinary game consider Fig. 5. It shows that the concept of $\mathrm{CrE}$ permits a certain amount of punishment.

Remark. An agent form subgame perfectness is not sufficient for credibility. A simple example is given in Fig. 6. (The arcs denote the credible deviation.)

\section{Some Properties of the Set of Credible Equilibria}

In this section we shall look more critically at the concept "credible equilibrium." We shall try to find flaws and investigate their seriousness. Take, first, the concept "credible deviation." Suppose $s$ is not credible.

\footnotetext{
${ }^{28}$ To be sure, the nonemptiness of APE was proved under the assumption that utility payments for each agent are defined at all endpoints. Because of Remark 3.4, we can assume that this is the case in our games, because we can add arbitrary payments for agents, off their path, without changing $\mathrm{CrE}$.
} 


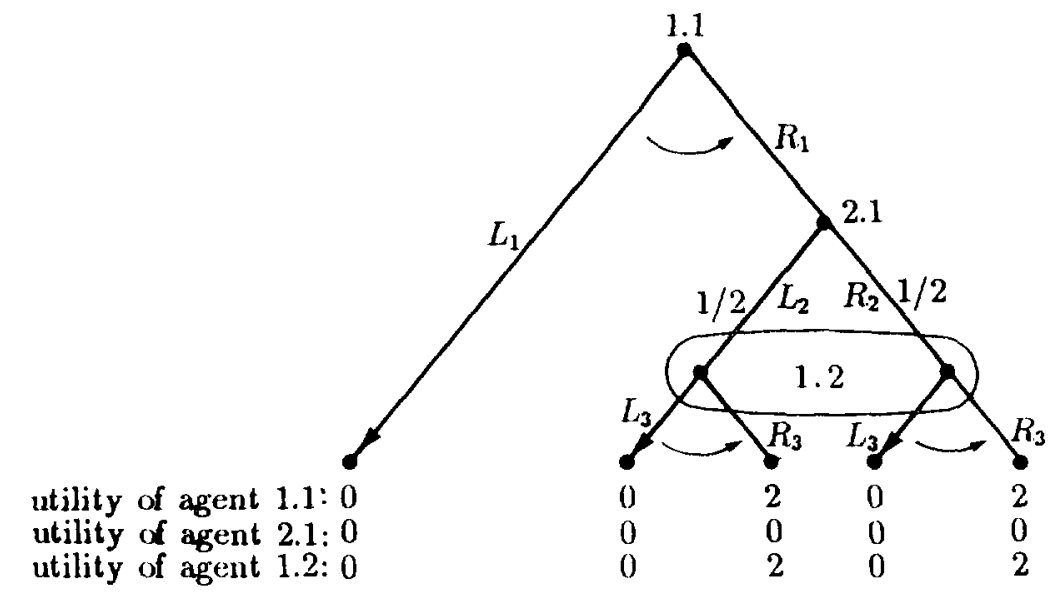

Fig. 6. An agent form subgame perfect equilibrium which is not in $\mathrm{CrE}$.

Can we always recommend a "best credible deviation"? The answer is negative as can be seen in Fig. 7.

Here, $s=\left(R_{1}, R_{2}, L_{3}\right)$ is not credible. The only credible deviations are those struck by agent 1.1 , instructing all the agents to move to $s^{\prime}:=\left(L_{1}\right.$, $\left.L_{2},\left[\left(\frac{1}{2}-\varepsilon\right) M_{3},\left(\frac{1}{2}+\varepsilon\right) R_{3}\right]\right), 0<\varepsilon<\frac{1}{2}$. Note that $s^{\prime}$ is a credible equilibrium. Of course, agent 1.1 would like to choose $\varepsilon$ as small as possible, but he cannot take $\varepsilon=0$, because then 1.2 will not cooperate. Note that this is

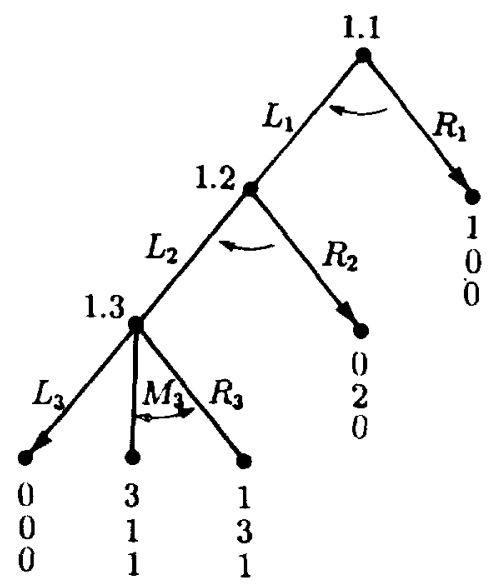

FIG. 7. A case in which there does not exist a best credible deviation. 
utility of agent 1.1: 1 utility of agent 1.2:0 utility of agent $2.1: 0$

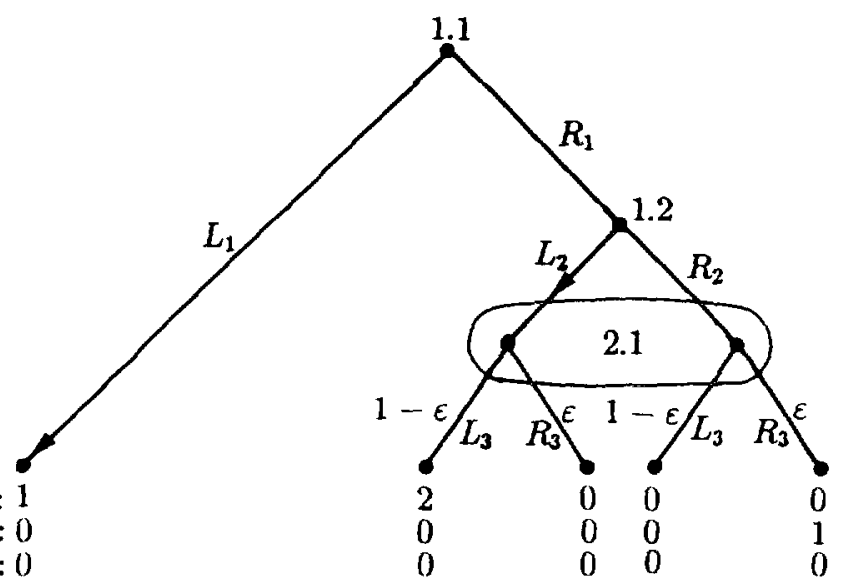

Fig. 8. A case in which $\mathrm{CrE}$ is not a closed set.

a consequence of the position we took in Definition 3.1, that cooperation can only be taken if there is real gain.

A more serious criticism, at least aesthetically, is the fact that $\mathrm{CrE}$ is not necessarily closed. Consider, for example, the 2-person game in Fig. 8 , in which agents 1.1 and 1.2 move $L_{1}$ and $L_{2}$, and agent 2.1 mixes between $L_{3}$ and $R_{3}$ with probabilities $(1-\varepsilon, \varepsilon)$. For every $\varepsilon, 0<\varepsilon \leq 1$, this is a credible equilibrium. It ceases to be, if $\varepsilon=0$.

Note that this example hinges on our conservative stand that an agent will cooperate only in face of a gain.

In Section 3 we presented an example of a credible deviation (Example 3.2) that was certain to be violated by the deviating agent himself. This was possible because of the need to keep Definition 3.1 recursive and, therefore, meaningful. We argued that, nevertheless, each agent of $Q$, after $i . j_{0}$, would still prefer to obey $s_{Q}^{\prime}$. Fortunately, we do not have to defend this argument any further, in view of the following theorem which shows that we may just as well restrict $s_{Q}^{\prime}$ to cases in which $i . j_{0}$ too cannot further violate.

THEOREM 5.1. If $s_{Q}^{\prime}$ is a credible deviation from $s$ by an agent $i . j_{0}$, then there exists a deviation $s_{G}^{*}$ from $s$, by the same agent, such that he too cannot strike a credible deviation from $s^{*}:=\left(s_{G}^{*}, s_{-G}\right)$.

Proof. The proof involves several steps.

Step 1 . Denote by $A^{\prime}$ the set of pure choices used by $i . j_{0}$ with positive probability under $s_{i, j_{0}}^{\prime}$. We can and do assume that by playing $s_{i, j_{0}}^{\prime}$ agent 
$i . j_{0}$ is maximizing under the condition that he must choose from $A^{\prime}$ and that all the agents that play after him (not necessarily only agents of $i$ ) obey $s^{\prime}$. Indeed, if not, replace $s_{i, j_{0}}^{\prime}$ by $\tilde{s}_{i, j_{0}}^{\prime}$ in which $i . j_{0}$ is maximizing under the restrictions stated above. Let $\tilde{Q}$ be a subset of $Q$, reached with positive probability under $\tilde{s}:=\left(\bar{s}_{i, j_{0}}, s_{\left.Q \backslash i j_{0}\right\}}^{\prime}, s_{-Q}\right)$ and not containing $i, j_{0}$. The combination $\left(\tilde{s}_{i, j_{0}}^{\prime}, s_{Q}^{\prime}\right)$ is a credible deviation from $s$, struck by $i, j_{0}$, which satisfies the maximizing requirement.

Step 2. Denote by $B$ the set of all agents of $i$ that play after $i, j_{0}$ and are reached with positive probability under $s^{\prime}$. Denote by $C$ the set of all agents of $i$ that follow pathwise agents of $B$, but reached with probability 0 under $s^{\prime}$.

We shall show that if there exists a credible deviation $s_{D}^{\prime \prime}$ from $s^{\prime}$, struck by $i . j_{0}$, then $D \cap(B \cup C)=\varnothing$. Suppose $D \cap B \neq \varnothing$ then there is a last agent $i . j_{1}$ in $D \cap B$; i.e., an agent such that those that follow him, and play differently under $s^{\prime}$ and $s^{\prime \prime}$, are reached with probability 0 under $s^{\prime}$. Let $D^{*}$ consist of $i . j_{1}$ and the agents in $D$ that play after him. We claim that $s_{D^{*}}^{\prime \prime}$ is a credible deviation from $s^{\prime}$, struck by $i . j_{1}$-thus arriving at a contradiction because $s^{\prime}$ was credible. To verify the claim, observe that condtions (ii) and (iii) of Definition 3.1 are satisfied for $s_{D^{*}}^{\prime \prime}$, because $s_{D}^{\prime \prime}$ was a credible deviation struck by $i . j_{0}$ and because every player after $i . j_{1}$ is also a player after $i . j_{0}$. More care is needed to verify condition (i). Consider the game $\Gamma_{i, j_{1}}^{s^{\prime}}$ and denote by $\tilde{s}^{\prime \prime}$ the restriction of $s^{\prime \prime}$ to this game. We know that in $\Gamma_{i, j_{1}}^{s^{\prime}}, \tilde{s}^{\prime \prime}>_{i, j_{1}}\left(\tilde{s}_{-\left\{i, j_{1}\right\}}^{\prime \prime}, s_{i, j_{1}}^{\prime}\right)$, because $\tilde{s}_{D}^{\prime \prime}$ was a credible deviation from $s^{\prime}$, struck by $i, j_{0}$ and $i, j_{1}$ plays after him (and is reached with positive probability both under $s^{\prime}$ and under $s^{\prime \prime}$ ). What we have to show is that in $\Gamma_{i, j_{1}}^{s^{\prime}}, \tilde{s}^{\prime \prime}>_{i, j_{1}}\left(s_{-\left\{i, j_{1}\right\}}^{\prime}, s_{i, j_{1}}^{\prime}\right)$. This, in fact, is the case, because $i . j_{1}$ was a last agent in $D \cap B$. Thus, in $\Gamma_{i, j_{1}}^{s^{\prime}}$, every agent $i . j$ after $i . j_{1}$, for whom $s_{i, j}^{\prime \prime} \neq s_{i, j}^{\prime}$, is reached under $s^{\prime}$ with probability 0 , so there is no change in payoffs if we require such agents to play $s_{i, j}^{\prime \prime}$ instead of $s_{i, j}^{\prime}$.

Since $s_{i, j}^{\prime \prime}=s_{i, j}^{\prime}$ for every agent in $B$, it follows that every agent in $C$ is reached with probability 0 under $s^{\prime \prime}$, therefore $D \cap C=\varnothing$.

Step 3. We have shown that $s^{\prime \prime}=s^{\prime}$ on paths after $i . j_{0}$, reached with postive probability under $s^{\prime}$ and their continuations. Thus, the support $A^{\prime \prime}$ of $s_{i, j_{0}}^{\prime \prime}$ must contan choices other than the choices in $A^{\prime}$, then $A^{\prime \prime} \cap A^{\prime}=$ $\varnothing$ and $s^{\prime \prime}$ directs the play to paths disjoint from those reached with positive probability under $s^{\prime}$ and their continuation. As in Step 1, we can and do assume that $i . j_{0}$ is maxmizing given that he is restricted to $A^{\prime \prime}$ and the other agents play according to $s^{\prime \prime}$.

Step 4. If there exists a credible deviation $s_{E}^{\prime \prime \prime}$ from $s^{\prime \prime}$, struck by $i . j_{0}$, then, as in Step 2, $E \backslash\left\{i, j_{0}\right\}$ does not contain agents of $i$ reached under $s^{\prime \prime}$ with positive probability or agents of $i$ that follow such agents. By arguments similar to those given in Step 2, it does not contain agents of $i$ reached with positive probability under $s^{\prime}$, and pathwise followers of such 


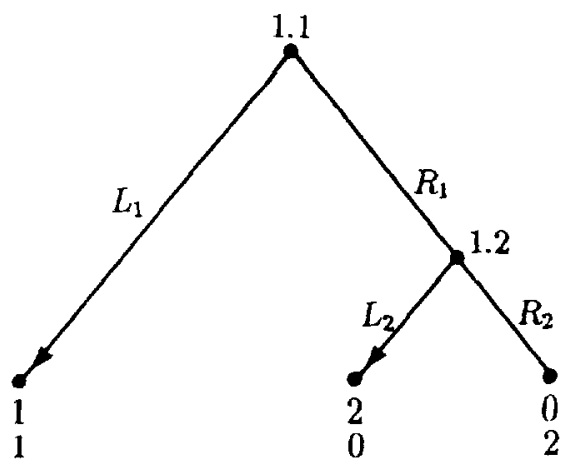

FIG. 9. A credible equilibrium which is not in ANE.

agents. Thus, if $s_{i, j_{0}}^{\prime \prime \prime}$ is maximizing on its support, it directs the play to paths different from the paths supported by $s^{\prime}$ or $s^{\prime \prime}$.

Step 5 . We continue in this fashion until we reach a credible deviation $s_{G}^{(k)}$ from an $s_{F}^{(k-1)}$, struck by $i . j_{0}$ and player $i . j_{0}$ cannot strike a credible deviation from $s_{G}^{(k)}$, neither alone, restricted to the support of $s_{i, j_{0}}^{(k)}$, nor by directing the play to other paths, because such paths are not available.

Step 6. $s_{G}^{(k)}$ is also a credible deviation from $s$, struck by $i . j_{0}$. Indeed by transitivity, $s^{(k)}>_{i, j_{0}} s^{(k-1)}>_{i, j_{0}} \cdots>_{i, j_{0}} s^{\prime}>_{i, j_{0}} s$; for every agent $i . j$ of $G$, $s_{i, j}^{(k-1)}$ is identical to $s_{i, j}$ and he prefers to comply with $s^{(k)}$; and neither $i . j_{0}$ nor his followers can strike a credible deviation.

A credible equilibrium need not be ANE, because agents off the paths of the play may sometimes act "irrationally." Figure 9 provides such an example. However, if one thinks this is undesirable, one can find comfort in the following theorem.

THEOREM 5.2. The paths that are supported by a credible equilibrium are also supported by a credible equilibrium which is also a Nash equilibrium for the agent form game.

Remark 5.3. The importance of Theorem 5.2 lies in the fact that people may feel uneasy agreeing on a credible equilibrium which is not Nash equilibrium for the agents. This theorem states that they can enjoy both worlds: They can agree on an ANE which is also credible. Moreover, the paths according to such agreements as well as the payoffs will be the same as those that did not insist on an ANE, so nothing will be lost by this restriction.

For the proof we need the following. 
LeMMA 5.4. Let $s$ be a credible equilibrium and let $i$ be a player. There exists an n-tuple of strategies $\tilde{s}$, such that

(1) $\tilde{s}$ induces the same probability distribution as $s$ on the set of nodes. In fact, it coincides with $s$ at all information sets reached under $s$ with positive probability.

(2) Every agent i.k of $i$ is maximizing in $\tilde{s}$, namely he is maximizing his expected payoff given that all other agents obey $\tilde{s}$.

(3) $\tilde{s}$ is a credible equilibrium.

(4) Every agent $j . k, j \neq i$, if he was maximizing under $s$, he is still maximizing under $\tilde{s}$.

Proof. As usual, we consider $s_{-i}$ fixed and known to player $i$. We construct $\tilde{s}$ successively, backwards eliminating agents $i . k$ who are not maximizing.

Let $i . k$ be a last agent who is not maximizing. Temporarily replace $s_{i . k}$ by a pure strategy $\hat{s}_{i, k}$ which is a best reply for him. This necessarily directs the play to paths not supported by $s$, because $s$ was a credible equilibrium. Along these new paths we modify $s$ by backward induction on the agents of $i$, after $i . k$, instructing each of them to employ best reply, given that he is reached, ${ }^{29}$ and keeping with $s$ whenever there is indifference and whenever he cannot be reached. Agent $i . k$ cannot gain by these modifications, compared to $s$, because if he could, he could also strike a credible deviation from $s$, giving himself and his followers the same instructions. So we let him revert to $s_{i . k}$. The resulting modification satisfies (1) with $\tilde{s}$ being the modified strategy $n$-tuple. It is also credible, because all modifications were done on unreachable paths that only $i . k$ could direct to them, which he would not because it were not profitable.

Agent $i . k$ may perhaps, still gain by picking up another pure strategy instead of $\hat{s}_{i, k}$. We eliminate such avenues successively in a similar fashion until eventually $i . k$ is maximizing with respect to the modified strategy $n$ tuple.

This process is repeated until all agents of $i$ are maximizing and so (1)-(3) are satisfied.

For agents of other players, if they are off the support of $s$ (which is also the support of $\bar{s}$ ), they are maximizing automatically. If they are in the support and maximizing under $s$, they are also maximizing under $\tilde{s}$, because $s=\tilde{s}$ in the support and they cannot lead the game to paths where $s \neq \tilde{s}$. This is condition (4).

\footnotetext{
${ }^{29}$ We remind the reader that if an agent is reached, then, because the game is of perfect recall, he can compute the probabilities of reaching each node of his information set and these probabilities depend only on $s_{-i}$.
} 


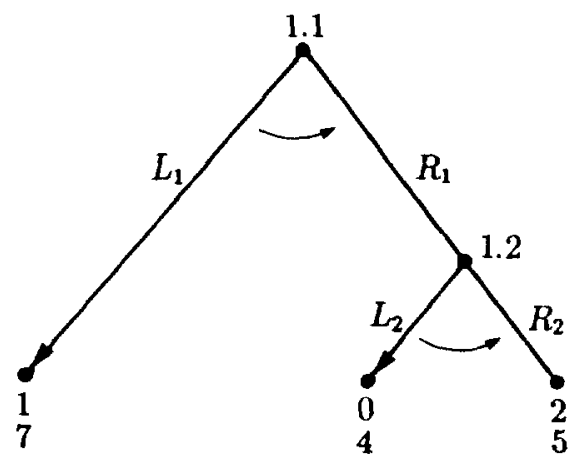

Fig. 10. A credible deviation that harms an agent.

Proof of Theorem 5.2. Apply the lemma consecutively for all the players. The final modification will be in ANE, because every agent will be maximizing. Moreover, this modification coincides with $s$ on the paths supported by $s$.

\section{EXAMPLES}

The purpose of the examples in this section is to illustrate some features of the credible deviations and get a better understanding of them.

EXAMPLE 6.1. Strategy $\left(L_{1}, L_{2}\right)$ in Fig. 10 is not credible despite the fact that agent 1.2 receives less than the original payment under the credible deviation $\left(R_{1}, R_{2}\right)$. Here we see the importance of the timing of decisions. When 1.2 plays, he has no alternative but to comply with the deviation. Thus, within the agents of a given player, the concept of credible equilibrium has some flavor of perfection, although in general, as we have seen, CrE may even contain points not in ANE.

Example 6.2. Strategy $\left(L_{1}, L_{2}\right)$ is credible in the game of Fig. 11. An instruction $\left(R_{1}, R_{2}\right)$ by agent 1.1 , although promising to increase agent 1.2's payoff, is not safe for agent 1.1 When agent 1.2 comes to play he has no motivation to move to $R_{2}$. In Section 8 we shall propose other variants under which $\left(R_{1}, R_{2}\right)$ will be considered credible deviation.

Example 6.3. Consider the game in Fig. 12. Here, player 1 is the head of the workers' union in a large firm. He can refrain from certain actions which we denote as $s_{1}$ and $s_{3}$ as these will save money for the firm. Or he can increase his popularity if he begins preparations for a 


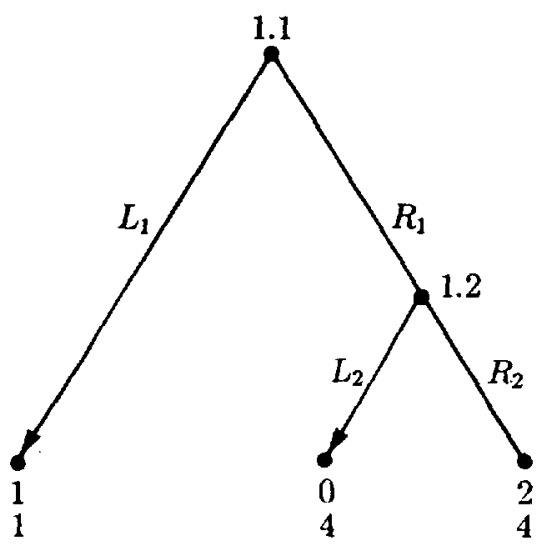

FiG. 11. A credible equilibrium which is not Pareto optimal.

strike (action $c_{1}$ ) and be even more popular if eventually he organizes a strike (action $c_{3}$ ). The preparations, although consuming from the firm's resources, will not be noted for a while by the owner of the firm-player 2. They are essential if a strike is to take place.

As said before, at 1.2 the head can convince the workers to declare a strike that will cause great damage to the firm. Anyhow, it will increase head's popularity.

The owner has two options. He can refrain $\left(s_{2}\right)$, or he can give significant bonuses to his employees (action $c_{2}$ ), to be revealed after the danger of a strike is over. This will increase his popularity, but, of course, will cost money to the firm. In fact, the owner can use this money to satisfy the workers demands. This is why we placed a utility payoff 4 for him, whether he pays the bonuses with, or without a strike. If no bonuses are given, the strike is going to be ferocious and the owner expects great damage ( 0 utility payment).

If saving takes place all the way $\left(s_{1}, s_{2}, s_{3}\right)$, the firm will have enough money to buy a new machine that will ease the workload of the workers and also increase production and earn more profits to the owner. This is what the owner prefers most. If there is only a partial saving $\left(c_{1}, s_{2}, s_{3}\right)$, the firm can afford only a smaller machine that will make the workload easier, but will not generate increased profits to the firm. In all other cases, there will not be enough money to buy any machine.

The head does not really want to cause a strike, provided the workers get the small or the big machine $(6>0,7>3$, and $8>5)$. Otherwise he does prefer to strike $(3>1$ and $5>2$ ). He does prefer, however, that a smaller machine be bought rather than the larger one $(7>6)$, because of 


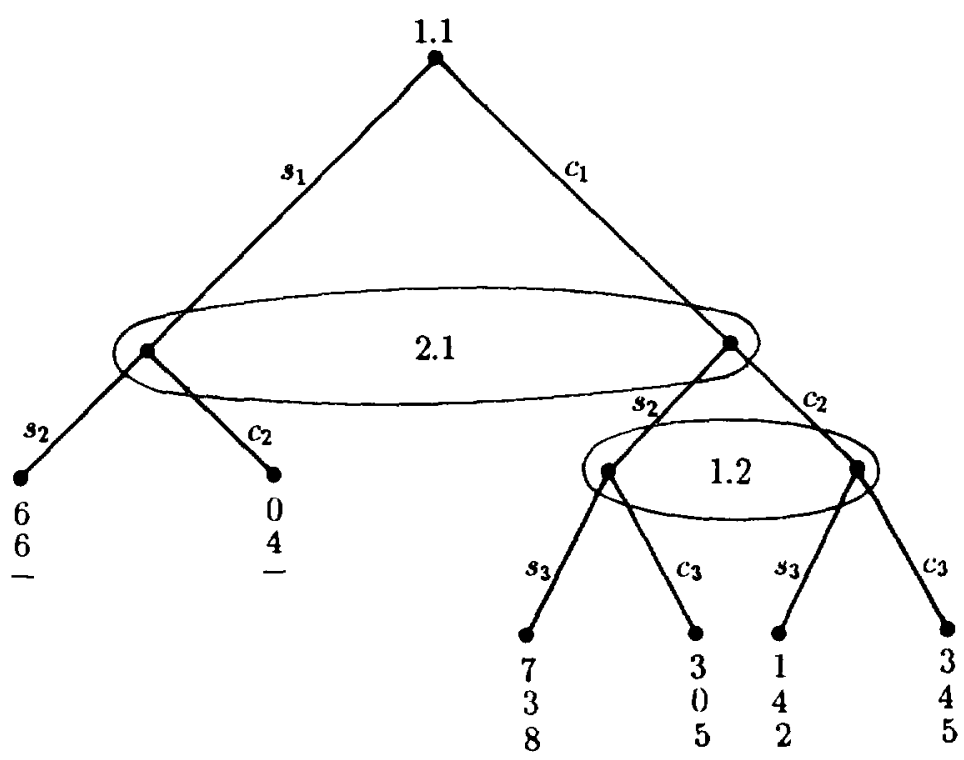

Fig. 12. The strike/no-strike game.

his increased popularity from $c_{1}$ and because the workload for the workers is the same, whether a large machine is bought, or a small one.

We are coming now to an important ingredient: The head expects that some amount of change in his personality will take place if he starts preparing for a strike $\left(c_{1}\right)$ : He will be engulfed with love from his workers, he will be carried away, and his willingness to cause a strike will look somewhat more desirable to him. (Power corrupts, they say.) This is why we put $8>7,5>3$ (twice), and $2>1$. He will simply enjoy the love of his people and the desire to show that he has great power and his "appetite" for organizing the workers to a strike will also increase.

The owner cares only a little for the smaller machine. If he cannot afford the new machine. It does not increase his profits. He would rather use the money to give bonuses to the workers in order to avoid or mitigate the effects of the strike. This is denoted by $4>3$ and $4>0$.

The rest of the priorities are self-explanatory from the figure. For example, if the head does not make any preparation for a strike, the owner would rather buy the new machine than give bonuses $(6>4)$. Unfortunately he does not know that this is the case.

Clearly, $\left(s_{1}, s_{2}, s_{3}\right)$ is not credible: Head 1.1 switches to $c_{1}$. Similarly, $\left(c_{1}, s_{2}, s_{3}\right)$ is not credible: Owner will rather spend his money on bonuses. 
Thus, there is no chance of getting any machine using pure strategies. The point $\left(c_{1}, c_{2}, c_{3}\right)$ is credible. It yields $(3,4,5)$ to the agents-what a sad prospect of frictions and strikes in the firm (although not a ferocious strike).

But there exists a credible behavoral strategy that even allows for complete saving with positive probability. It is $\left(\left[\frac{2}{3}\left(s_{1}\right), \frac{1}{3}\left(c_{1}\right)\right],\left[\frac{1}{2}\left(s_{2}\right), \frac{1}{2}\left(c_{2}\right)\right]\right.$, $\left.c_{3}\right)$. Under this strategy the firm will buy the high-quality machine with probability $\frac{1}{3}$ and the small machine with probability $\frac{1}{6}$. The payoff of 1.1 will be 3 and it will be 4 to 2 .1. A strike will occur only with probability $\frac{1}{3}$ and be very damaging with half of this probability. Otherwise, bonuses will be given to mitigate the effect of the strike. Agent 1.2, if "created," will receive a payment 5 .

It is interesting to note that if agent 1.2 had the same utility function as that of 1.1 , the only equilibrium point would be $\left(c_{1}, c_{2}, c_{3}\right)$. The difference is that he is aware that he might be carried away once he starts preparing for a strike that is a priori not so pleasant. This awareness causes him to consider and agree to a mixed strategy credible equilibrium that gives a chance (probability $\frac{2}{3}$ ) to good firm-workers relations.

\section{Timewise Credible Equilibria}

The definition of credible deviation can be criticized on the following ground: In a classical game, a player has utility values also at endpoints he never reaches and these may play an important role in choosing his strategy. Why then we do not allow an agent, who wants to strike a deviation, to give instructions also to agents that do not follow him? He may have a utility function defined at endpoints that follow such agents. The following example seems at first convincing.

Example 7.1. This is a one person game with a chance move. It is given in Fig. 13.

After chance's move, either agent 1.1 , or agent 1.2 is being called to make a move, but each agent has a different utility function over the endpoints. ${ }^{30}$ The players consider $s=\left(L_{1}, L_{2}\right)$. On the face of it, it seems not "credible" in the following sense: Agent 1.1 can approach agent 1.2 with a proposal that agent 1.2 switches to $R_{2}$, if he is called to play. In return, agent 1.1 promises that he will switch to $R_{1}$, if he is being called to play. Is this a convincing deviation? We think not: If agent 1.1 is being called to play, he knows that agent 1.2 will not play and therefore there

\footnotetext{
${ }^{30}$ This is because they are being called to play at different dates; otherwise it makes no sense to envision that the same individual, at the same moment, has two different utility functions.
} 


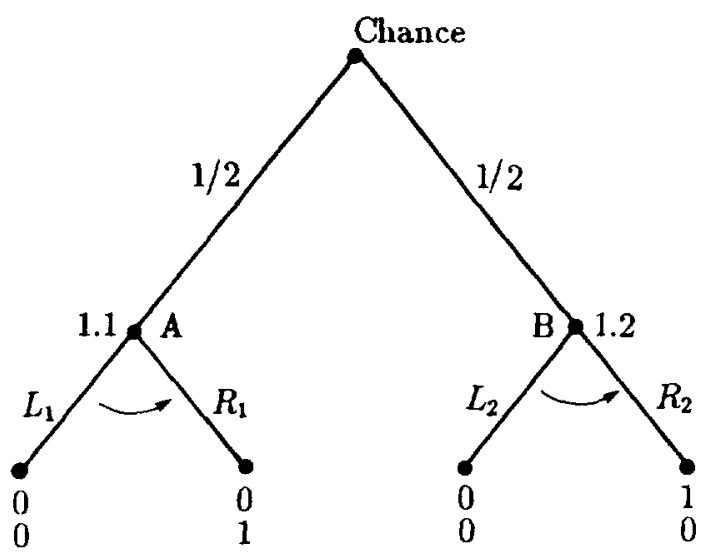

FIG. 13. A "counterexample."

is no reason for him to deviate from $L_{1}$, because there is no profit in such a deviation. Similarly, agent 1.2 will not deviate from $L_{2}$, because he does not gain by doing so. ${ }^{31}$

To do justice to the above criticism one has to extend the family of games, by introducing dates at each information set, with the provision that agents of the same player, who are being called to make a move at the same date, have the same utility function. One may want ${ }^{32}$ to add provisions that prohibit games which are impossible to play, such as the one in Fig. 14, which can occur only in science fiction, when the agents are equipped with "time machines."

For this family of games one can define the concepts of "timewise credible deviation" and "timewise credible equilibrium" in a way similar to the definition of Section 2 . The only changes are that $Q$ contains agent $i . j_{0}$, who strikes the deviation, and possibly agents of player $i$, who play timewise ${ }^{33}$ not earlier than $i . j_{0}$ and that timewise after he moves, no other agent of player $i$ can strike a timewise credible deviation.

With respect to these definitions we are able to prove the following. ${ }^{34}$

THEOREm 7.2. Let $\Gamma$ be a game of perfect recall with dates. Let $\Gamma^{*}$

${ }^{31}$ This argument fails when we work in the framework of the "optimistic credible equilibria" (see Section 8), where one is supposed to deviate even if the deviation yields no profits.

32 Although this is not essential for our purpose.

${ }^{33}$ As contrasted with pathwise. The latter implies the former, but not vice versa. Thus, an agent may give instructions to agents of the same player, playing after him, provided that they had not already made their move.

${ }^{34}$ The proof will be omitted for the sake of brevity. 


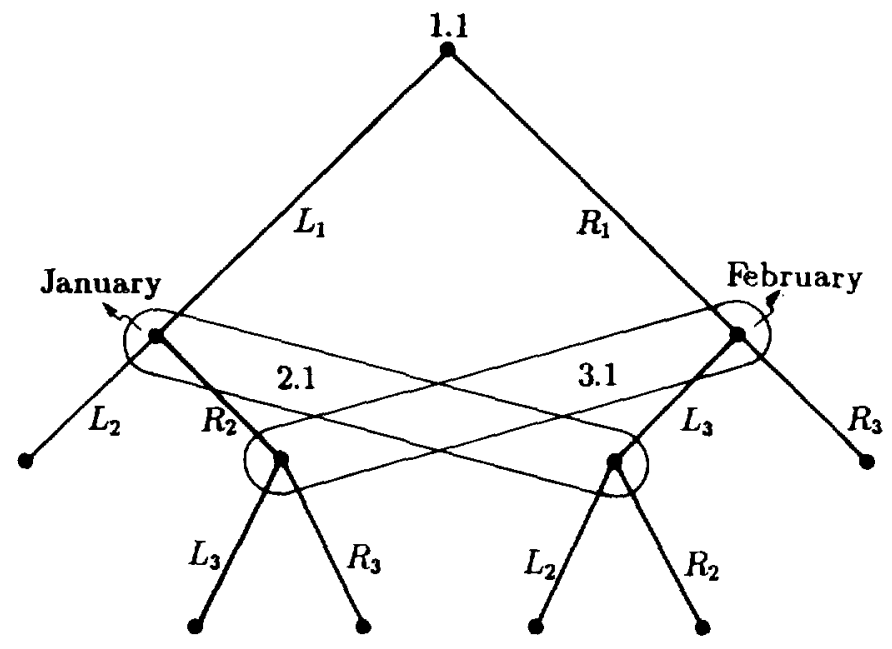

FIG. 14. A game that is impossible to play.

be the game, obtained from $\Gamma$ by removing the dates. The set of timewise credible equilibria of $\Gamma$ is identical with the set of (pathwise) credible equilibria of $\Gamma^{*}$.

Remark 7.3. Note that the game of Fig. 14, with dates removed, makes perfect sense. Both agents 2.1 and 3.1 are required to act without knowing if the other has already made his move.

\section{OTHER VARIANTS}

In Section 3 we took the position that when an agent in the deviating coalition is indifferent to complying with $s^{\prime}$ or with $s$, he will not switch. This position gave rise to requirement (ii) in Definition 3.1. We could take the other position, that he will comply with $s^{\prime}$ in case of indifference. After all, what one promises to oneself is perhaps more important than what one promises to others. With this position in mind, an interesting variant may be to omit requirement (ii) altogether. Accordingly, we shall call a deviation $s_{Q}^{\prime}$ satisfying (i) and (iii) of Definition 3.1 an optimistic credible deviation ${ }^{35}$ and we define an optimistic credible equilibrium as an $n$-tuple of strategies from which there do not exist optimistic credible

\footnotetext{
${ }^{35}$ Replace "credible deviation" in condition (iii) by "optimal credible deviation."
} 


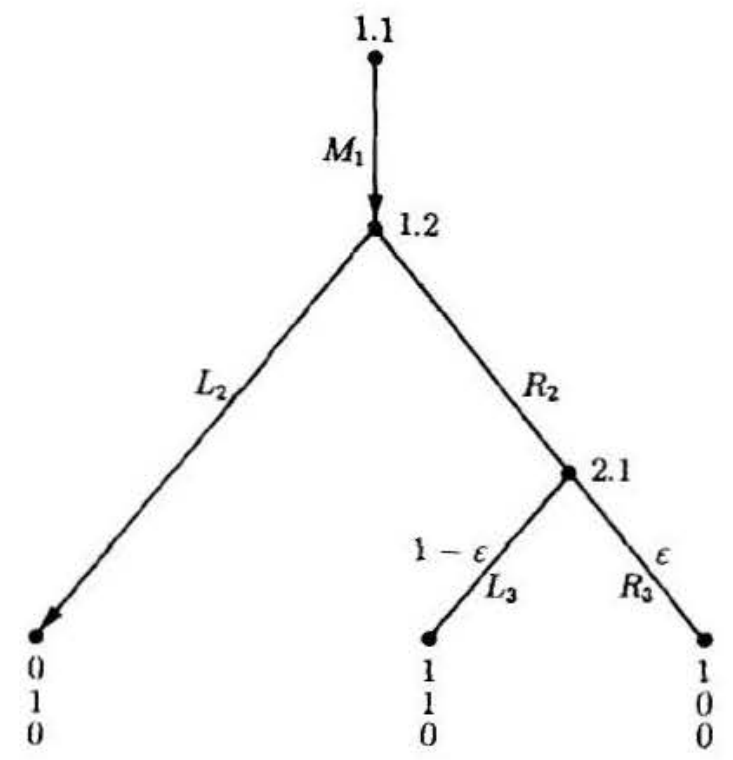

FIG. 15. An OCrE which is not closed.

deviations. Condition (i) assures us that it is worthy to agent $i, j_{0}$ to strike the deviation if other members of $Q$ obey him. Condition (iii) asserts that he can be reasonably sure that they will and that other agents of $i$, who play after him will keep to $s$, because none of them can profit by striking an optimal credible deviation.

The set of optimistic credible equilibria (OCrE) coincides with $\mathrm{NE}$ in ordinary games, and the proof is essentially the same as in Theorem 4.1. Thus, OCrE is also an extension of the Nash solution concept. It, too, is not necessarily a closed set as the example in Fig. 15 shows.

In this example $\left(M_{1}, L_{2},\left[(1-\varepsilon) L_{3}, \varepsilon R_{3}\right]\right)$ is in $\mathrm{OCrE}$ whenever $0<$ $\varepsilon \leq 1$ but if $\varepsilon=0$, agent 1.1 can instruct agent 1.2 to move right, and this is an optimistic credible deviation.

We believe that $\mathrm{OCrE}$ is worth studying, because of its simpler definition as compared to $\mathrm{CrE}$ and because it yields interesting strategies. The set OCrE need not contain APE and the game in Fig. 16 is an appropriate example.

Here, $\left(M_{1}, L_{2}, L_{3}\right)$ is the unique perfect equilibrium point for the agent form game. It is not optimistically credible because 1.1 can instruct 1.2 to move right. The point $\left(M_{1}, R_{2}, L_{3}\right)$ is both in $\mathrm{CrE}$ and in OCrE.

Unfortunately, OCrE may be empty, as can be seen in the game of Fig. 17. 


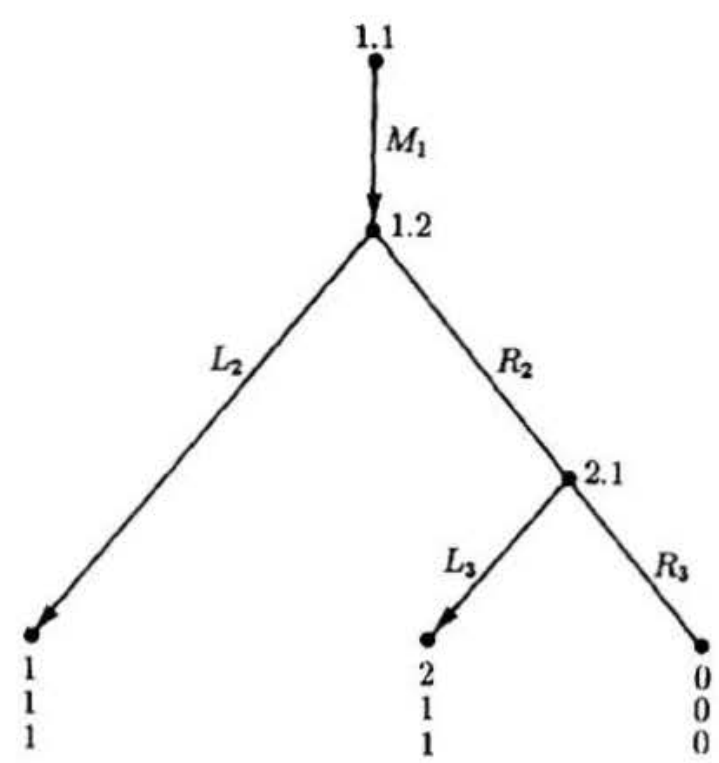

FIG. 16. An example in which $\mathrm{OCrE} \cap \mathrm{APE}=\varnothing$.

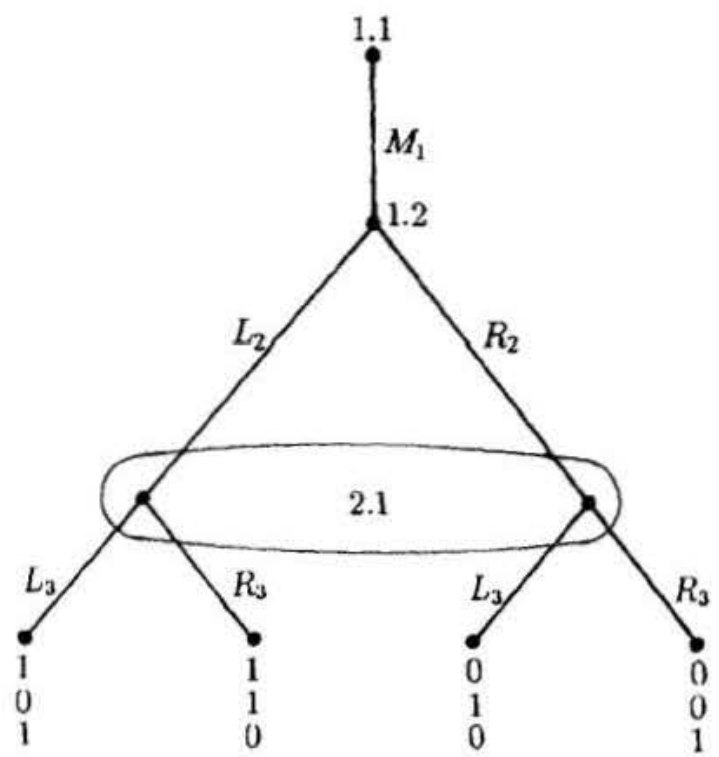

Fig. 17. A game with an empty OCrE. 
In this example 1.2 and 2.1 play matching pennies. Thus, if $s \in \mathrm{OCrE}$ then $s_{1.2}=\left(\frac{1}{2}, \frac{1}{2}\right)$ and $s_{2.1}=\left(\frac{1}{2}, \frac{1}{2}\right)$. But then, 1.1 can strike an optimistic credible deviation by instructing 1.2 to move "left." One may feel that this counterexample is sufficient to discard OCrE. We do not think so. $\mathrm{OCrE}$ conceptually is simpler than $\mathrm{CrE}$ and if it does contain some points, these may have some advantage.

In another variant of the $\mathrm{OCrE}$ concept, one requires that in case of indifference between complying with $s^{\prime}$ and complying with $s$ in $\Gamma_{i, j}^{s^{\prime}}$, $i . j \in Q$, agent $i . j$ will comply with $s^{\prime}$ only if, when the instruction was given, agent $i . j$ was promised some gain in $s^{\prime}$ as compared to $s$. It is as if $i . j_{0}$ "tells" $i . j$ in $Q$ : "If I would not have struck the deviation and we all played according to the original point $s$, you would have received a certain amount, $a$. Now that I strike the deviation, you will get $b$, and $b$ is greater than $a$. True, when it will be your turn to play you will get $b$ even if you play $s_{i, j}$, but where will your gratitude to me-your own flesh and blood--be for the profits I threw upon you?" We feel that this concept should also be studied, but we must say that it has one drawback: It requires utilities of agent $i . j$ to be defined even if $s$ is played, perhaps under outcomes in which $i . j$ is not even created.

\section{OTher APPLiCations}

Up to now we restricted ourselves to one scenario: The players are individuals who play a game in extensive form and their utilities may change during the play. But the model that we constructed may be useful in other applications. In this section we shall discusss two of them.

A. Violation of von Neumann-Morgenstern Independence Axiom. The last decade, which has witnessed a proliferation of studies of generalizations of von Neumann-Morgenstern (1947) expected utility theory, saw a revival of interest in the changing-preference problem. Indeed, in many models, the violation of von Neumann-Morgenstern independence axiom is equivalent to dynamic inconsistency in decision makers' preferences in a multi-stage decision problem under risk (see Hammond, 1988; Karni and Safra, 1989a, 1989b; Machina, 1989). Differently put, the violation of the axiom is (at least technically) equivalent to a change in the decision-maker's utility function (over lotteries). Thus, our concept of $\mathrm{CrE}$ may be applied to such models as well.

B. Application to the Theory of Organizations. In many game models, a player is not an individual. It can be a state, a political party, a firm, etc.-in short, an organization. In such cases almost always it makes no sense to attribute to such an organization a von Neumann-Morgenstern 
utility function. We do not refer here only to situations that fall under Condorcet paradox (Condorcet, 1785), but to a more fundamental fact that a non-individual player may not have priorities of its own. What is the utility function of a state?, Is it the utility of the farmers?, The utility of the manufacturers?, The white collar people?, The plain citizens?, The prime minister? When analyzing such situations one has two options ${ }^{36}$ : One option is to treat all the individuals in each organization as the players of the game and the other option is to treat each organization as a single 'decision-making unit' that represents 'agents' each having a different utility function. ${ }^{37}$

Often, the first option yields an extremely complicated game, not amenable to meaningful treatment; there are too many players and different communication patterns if members of the same organization are concerned and if members of different organizations are concerned. Often all this information is not even fully known. Shall we treat a game between Coca Cola and Pepsi Cola as a game involving all employees of these industries? Even if one can derive results for such games the analysis will hardly be insightful.

Thus, in many cases it is more expedient to regard the game as a game in which the organizations are the players, even though a lot of information may be lost in this way. Thus, under the second option we regard each organization as a player who is capable of choosing a strategy and giving instructions to the groups it represents (these groups are its agents) but he has to take into consideration their priorities, otherwise his instructions will not be obeyed. Each such group is capable of deviating from the instructions given by its organization, or by one of its agents, and it will deviate if it finds the deviation profitable and safe. In such situations a model similar to ours may be useful.

Applications of game theory in which players in the game model are not individuals are numerous and among the most important. In many cases classical game theory usually ignores the fact that preferences of the various agents may differ. This is not a sensible approach. As explained above, it may be infeasible to treat every individual as a player. If the model developed in this paper could be used to handle such situations, that would be a significant contribution to applied game theory. For example, a game theorist could tell the instruction-giving units (the organizations): "You can, of course, agree on any strategy combination, but only credible combinations will be abided by. Here, I computed for you a set of those combinations that are likely to be followed."

\footnotetext{
${ }^{36}$ We are grateful to the anonymous referee who suggested that this is clarified.

${ }^{37}$ One may even want to aggregate individuals who have a similar utility function into "one agent."
} 


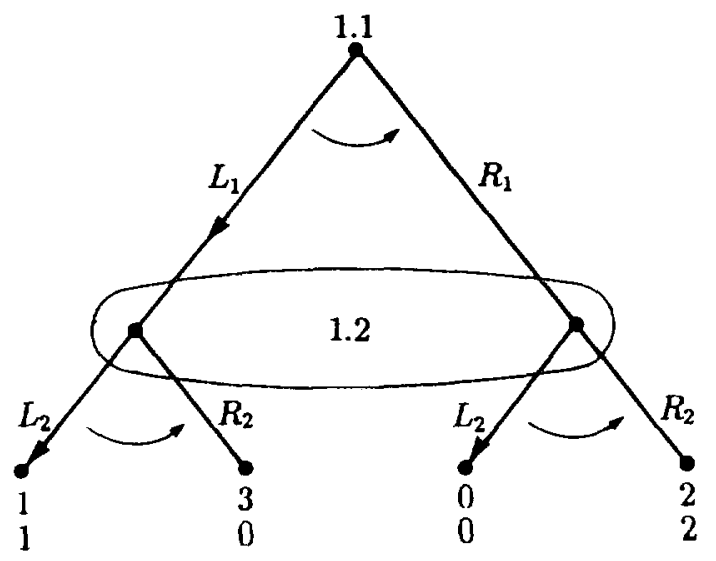

FIG. 18. A credible deviation that does not make sense.

We feel that the present model is quite convincing in those situations in which perfect recall prevails. We will recommend adopting only credible equilibria for treaties to be considered by the organizations. However, in many applications discussed here, perfect recall is not a reasonable requirement. Why should the farmers know what the manufacturers did in the past, where farmers and manufacturers are agents of one company, for example ${ }^{38}$ ? In such cases there are difficulties in our model. To begin with, one cannot limit oneself to behavioral strategies. But this is not the main difficulty. There are more basic ones: The concept itself is not convincing and requires a modification. Take, for example, the one-person game of Fig. 18. Here, $\left(L_{1}, L_{2}\right)$ is not credible because agent 1.1 can instruct himself and agent 1.2 to move right. If agent $1.2 \mathrm{knew}$ that agent 1.1 was moving right, he would have certainly chosen to comply. But he does not know, and if he complies, then it behooves agent 1.1 to remain at $L_{1}$ so as to get 3 . So, the deviation $\left(R_{1}, R_{2}\right)$ is perhaps not safe, despite the fact that it complies with Definition 3.1.

And there are other difficulties. For example, to be useful, the model should allow an agent to occupy several information sets, belonging to different dates, if dates are specified. It should be clear who plays after whom, so as to know to whom instructions of the deviating player can be given. The strategy space should also be clearly specified: Do we allow agents to use correlated strategies, for example? Suppose that the agents have agreed on a strategy combination and that some agents deviated in

${ }^{38}$ Of course, if the instructions can only by delivered publicly, as it should be in most cases of democratic societies, one can claim that perfect recall prevails. 
such a way that others do not know it, due to the imperfect recall. And suppose that, contrary to the agreement, an agent finds himself at an information set that should have been reached with zero probability. He knows that a violation has occurred but often does not know which one. How will he interpret the observation? We see that with lack of perfect recall all the problematic issues of "refinements" pop up despite the fact that our goal was to only generalize the Nash solution. Thus, applications of CE to games where a player represents several groups is at present limited. The extension of this model to games without perfect recall remains a challenging topic for further research.

\section{REFERENCES}

Allais, M. (1947), Economie et Interet. Paris: Imprimerie Nationale.

Aumann, R. J. (1985). "What is Game Theory Trying to Accomplish," in Frontiers of Economics (K. J. Arrow and S. Honkapohja, Eds.), pp. 28-87. Oxford, UK/New York: Blackwell.

Aumann, R. J., and Brandenburger, A. (1991). "Epistemic Conditions for Nash Equilibrium," Econometrica 63, to appear.

Bernheim, B. D., Peleg, B., And Whinston, M. D. (1987). "Coalition-Proof Nash Equilibria. I. Concepts," J. Econ. Theory 42, 1-12.

Blackorby, C., Nissen, D., Primont, D., and Russell, R. R. (1973). "Consistent Intertemporal Decision-Making," Rev. Econ. Stud. 40, 239-248.

Condorcet, M. J. A. (de Caritat, Marquis de). (1785). Essai sur l'application de l'analyse à la probabilité de décisions rendues à la pluralité de vois, Paris.

Hammond, P. J. (1976). "Changing Tastes and Coherent Dynamic Choice," Rev. Econ. Stud. 43, 159-173.

HAMmond, P. J. (1988). "Consequentialist Foundations for Expected Utility," Theory and Decision 25, 25-78.

Harsanyi, J. C. (1953). "Welfare Economics of Variable Tastes," Rev. Econ. Stud. 21, 204-213.

HaRSANYI, J. C. (1967-1968). "Games with Incomplete Information Played by 'Bayesian' Players," Parts I, II, III, Manage. Sci. 14, 159-182, 320-332, 468-502.

KARNI, E., AND SAFra, Z. (1989a), "Dynamic Consistency, Revelations in Auctions and the Structure of Preferences," Rev. Econ. Stud. 56, 421-434.

KARNi, E., AND SAFRA, Z. (1989b). "Ascending Bid Auctions with Behaviorally Consistent Bidders," Ann. Oper. Res. 19, 435-446.

Kunn, H. W. (1953). "Extensive Games and the Problem of Information," in Conribution to the Theory of Games, Annals of Mathematics Studies, Vol II (H. W. Kuhn and A. W. Tucker, Eds.), pp. 193-216. Princeton, NJ: Princeton Univ. Press.

Machina, M. (1989). "Dynamic Consistency and Non-expected Utility Models of Choice under Uncertainty," J. Econ. Theory 27, 1622-1668.

NaSh, J. F., JR. (1951). "Non-cooperative Games," Ann. of Math. 54, 289-295.

PeleG, B. (1992). "On Perfectly Coalition-Proof Nash Equilibria," in Equilibrium and 
Dynamics: Essays in Honor of David Gale (M. Majumdar, Ed.), pp. 259-268. London: Macmillan.

Peleg, B., And YaAri, M. E. (1973). "On the Existence of a Consistent Course of Action when Tastes are Changing," Rev. Econ. Stud. 40, 391-401.

Phelps, E. S., and Pollak, R. A. (1968). "On Second-Best National Saving and GameEquilibrium Growth," Rev. Econ. Stud. 35, 185-200.

Pollak, R. A. (1968). "Consistent Planning," Rev. Econ. Stud. 35, 201-208.

Pollak, R. A. (1970). "Habit Formation and Dynamic Demand Functions," J. Polit. Econ. 78, 745-764.

Pollak, R. A. (1976). "Habit Formation and Long-Run Utility Functions," J, Econ. Theory 13, 272-297.

SAVAGE, L. J. (1954). The Foundations of Statistics, 2nd rev. ed., (1972). New York: Dover. SCHOEffler, S. (1952). "Note on Modern Welfare Economics," Amer. Econ. Rev. 880-887.

SelteN, R. (1975). "Re-examination of the Perfectness Concept for Equilibrium Points in Extensive Games," Int. J. Game Theory 4, 25-55.

Strotz, R. H. (1956). "Myopia and Inconsistency in Dynamic Utility Maximization," Rev. Econ. Stud. 23, 165-180.

Von Neumann, J., AND Morgenstern, O. (1947). Theory of Games and Economic Behavior. Princeton, NJ: Princeton Univ. Press.

Von Weizsaecker, C. C. (1971). "Notes on Endogenous Changes of Tastes," J. Econ. Theory 4, 345-372. 